\title{
Sinüzoidal Darbe Genişlik Modülasyon Tekniği ile Beş Fazlı Asenkron Motorun Matlab/Simulink Modeli
}

\section{Matlab/Simulink Model of Five phase Induction Motor with Sinusoidal Pulse Width Modulation Technique}

\section{Ezgi TAŞKIN ${ }^{1 *}$, Mehmet ÖZDEMIR ${ }^{2}$, İsmail SARIGÜL ${ }^{3}$}

${ }^{1}$ Fırat Üniversitesi, Elektrik-Elektronik Mühendisliği Bölümü, ezgitaskin68@gmail.com, ORCID No: 0000-0002-7230-3401

${ }^{2}$ Fırat Üniversitesi, Elektrik-Elektronik Mühendisliği Bölümü, mozdemir@ firat.edu.tr, ORCID No: 0000-0002-1178-060X

${ }^{3}$ İnönü Üniversitesi, Elektrik-Elektronik Mühendisliği Bölümü, ismail.sarigul@inonu.edu.tr, ORCID No: 0000-0001-8440-5918

\begin{tabular}{|c|c|}
\hline MAKALE BİLGILERİ & ÖZET \\
\hline Makale Geçmişi: & \\
\hline $\begin{array}{l}\text { Geliş } 9 \text { Ağustos } 2021 \\
\text { Revizyon } 14 \text { Eylül } 2021 \\
\text { Kabul } 22 \text { Eylül } 2021 \\
\text { Online } 28 \text { Eylül } 2021\end{array}$ & $\begin{array}{l}\text { Günümüzde üç fazlı asenkron motorların kullanımı yaygın olmasıyla birlikte gelişen teknolojiye paralel } \\
\text { olarak çok fazlı ( } 3 \text { 'ten fazla) asenkron motor kavramı ortaya çıkmıştır. Çok fazlı asenkron motorlar } \\
\text { geleneksel üç fazlı asenkron motorlara göre birçok avantaja sahiptir. Özellikle yüksek güç gerektiren } \\
\text { uygulamalarda, elektrikli ve hibrit araçlarda, hava ve deniz taşıtlarında vs. kullanılmaktadı. Çok fazlı } \\
\text { asenkron motorlar genellikle inverterlerle beslenmektedir. İnverterin çıkışındaki harmonikler o dalganın }\end{array}$ \\
\hline $\begin{array}{l}\text { Anahtar Kelimeler: } \\
\text { 5-faz, asenkron motor, PWM, } \\
\text { sinüzoidal darbe genişlik } \\
\text { modülasyonu }\end{array}$ & $\begin{array}{l}\text { kalitesinin belirlenmesindeki en temel unsurdur. Harmonik bozulmaların önüne geçmek için çeşitli } \\
\text { yöntemler kullanılarak çıkış dalga şeklinin sinüse yakın olması amaçlanmaktadır. Bu yöntemlerden biri de } \\
\text { sinüzoidal darbe genişlik modülasyon tekniğidir. Bu çalışmada sinüzoidal darbe genişlik modülasyon } \\
\text { yöntemi ile beş fazlı asenkron motorun kontrolü yapılmıştır. Beş fazlı asenkron motora ait matematiksel } \\
\text { denklemler kullanılarak, beş fazlı asenkron motorun simulink model uygulaması d-q referans çerçevesinde } \\
\text { oluşturulmuştur. Benzetim modelleri MATLAB/Simulink paket programında gerçekleştirilmiştir. }\end{array}$ \\
\hline
\end{tabular}

\begin{tabular}{|c|c|}
\hline ARTICLE INFO & ABSTRACT \\
\hline Article history: & \\
\hline $\begin{array}{l}\text { Received } 9 \text { August } 2021 \\
\text { Received in revised form } 14 \text { September } \\
2021 \\
\text { Accepted } 22 \text { September } 2021 \\
\text { Available online } 28 \text { September } 2021\end{array}$ & $\begin{array}{l}\text { Today, with the widespread use of three-phase induction motors, the concept of multi-phase (more than } 3 \text { ) } \\
\text { induction motors has emerged in parallel with the developing technology. Multi-phase induction motors } \\
\text { have many advantages over traditional three-phase induction motors. Especially it is used in applications } \\
\text { requiring high power, electric air and sea vehicles, etc. Multiphase induction motors are generally fed with } \\
\text { an inverter. Harmonics at the output of the inverter are the most basic element in determining the quality }\end{array}$ \\
\hline $\begin{array}{l}\text { Keywords: } \\
\text { 5-phase, induction motor, } P W M, \\
\text { sinusoidal pulse width modulation }\end{array}$ & $\begin{array}{l}\text { of that wave. It is aimed to have the output waveform close to the sinus by using various methods to } \\
\text { prevent harmonic distortions. One of these methods is the sinusoidal pulse width modulation (SPWM) } \\
\text { technique. In this study, five-phase induction motor control was discussed using the sinusoidal pulse width } \\
\text { modulation technique. A model was created by using the mathematical equations of the five-phase } \\
\text { induction motor, and then a 5-phase supply source model was created. Simulation models were created in } \\
\text { MATLAB / Simulink package program. }\end{array}$ \\
\hline
\end{tabular}

Doi: 10.24012/dumf.1002124 


\section{Giriş}

Günümüzde üç fazlı şebekeye erişim kolay olduğundan küçük güçlerde tek fazlı asenkron motorun kullanımının dışında asenkron motor daha çok üç fazlı olarak üretilir. Teknolojinin gelişmesine bağlı olarak güç elektroniği alanındaki ilerlemelerle birlikte yarı iletken anahtarlardaki iletim ve anahtarlama kayıpları azalmıştır. Bu nedenden dolayı asenkron motorlarda verimlilik artışı söz konusu olmuştur. Bu gelişmelere paralel olarak çok fazlı asenkron motor kavramı hayatımıza girmiştir. Çok fazlı asenkron motorlar geleneksel üc fazlı asenkron motorlar ile kıyaslandığında birçok avantaja sahiptir.

$\mathrm{Bu}$ avantajlardan bazıları şunlardır;

- Faz sayısı arttıkça gerekli olan güç fazlar arasında bölündüğünden güç taşıma kapasitesi daha yüksek olur,

- Tork titreşimi azalır,

- Daha fazla güvenilirliğe sahip olur,

- Statorda meydana gelen faz kaybı, motorun çalışma ve başlama durumunu engellemez,

- Aynı boyuta sahip motora göre amper başına üretilen moment artar,

- Stator bakır kaybında azalma meydana gelir,

- $\quad$ Rotor harmonik akımı azalır [1],

- Bir veya iki fazı kısa devre ya da açık devre olsa bile çalışabilir [2].

Çok fazlı asenkron motor sürücülerinin ana uygulama alanlarına;

- Elektrikli veya hibrit araçlar,

- Elektrikli trenler ve gemiler,

- Hava taşıtları,

- Uzay araçları ve

- Yüksek güç gerektiren uygulamalar örnek olarak verilebilir [3].

\section{Materyal ve Yöntem}

Bu bölümde çalışmada kullanılan beş fazlı asenkron motor, beş fazlı inverter ve inverter modelinde kullanılan modülasyon tekniği hakkında bilgi verilmektedir. Beş fazlı asenkron motorun matlab/simulink model uygulaması $\mathrm{d}-\mathrm{q}$ referans çerçevesinde oluşturulmuştur.

\section{Beş fazlı asenkron motor}

Beş fazlı asenkron motorun çalışması, üç fazlı asenkron motorun çalışmasına benzerdir. Aralarındaki tek fark beş fazlı asenkron motorun beş fazlı bir alternatif akım (AA) sinyaline ihtiyaç duyması ve statorunda beş fazlı sargı yapısının bulunmasıdır. Dengeli bir beş fazlıda, beş grup stator sargısı $72^{\circ}$ aralıklarla dağıtılır. Üç faz sargı yapısına göre her iki faz arasındaki faz farkının daha az olması motorun daha yüksek bir güç yoğunluğuna katkıda bulunur [4]. Şekil 1 'de 5 fazlı asenkron motorun şematik diyagramı verilmiştir.
Asenkron motorun stator sargısına beş faz besleme gerilimi uygulandığı zaman, stator sargılarında senkron hız ile dönen bir döner manyetik alan oluşur. Her iki taraftan kısa devre edilmiş rotor çubukları, bu dönen manyetik alan içerisinde bulunduğundan, elektromanyetik endüksiyon yasasına göre rotor çubuklarında bir gerilim indüklenir. $\mathrm{Bu}$ indüklenen gerilim nedeniyle, rotor çubuklarından rotor akımı akmaya başlar ve rotorda da bir manyetik alan oluşur. Bu iki manyetik alanın etkileşimi nedeniyle bir moment üretilir [5]. Manyetik alan içerisinde bulunan iletkenden akım geçtiğinde BiortSavart yasasına göre iletkene bir kuvvet etki eder ve bu kuvvet iletkeni hareket ettirmeye çalışır. Böylece motorun hareket ilkesi açıklanmış olur [6].

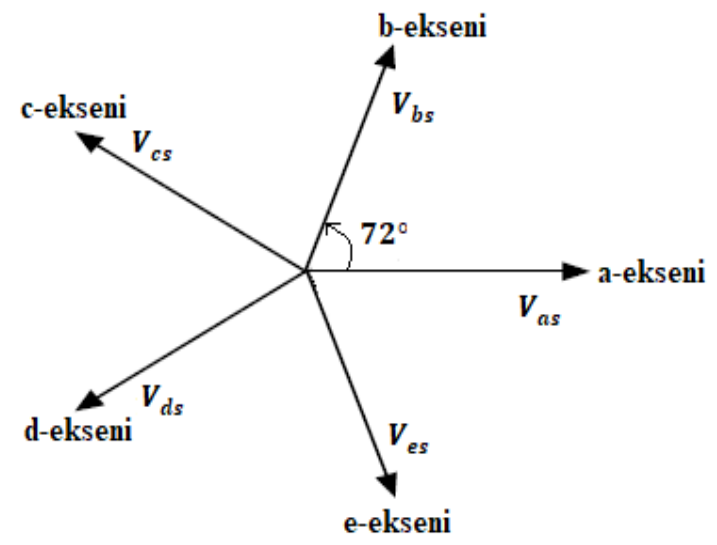

Şekil 1. Beş fazlı asenkron motorun şematik diyagramı

\section{5 fazlı gerilim kaynaklı inverter}

Şekil 2‘de beş fazlı gerilim kaynaklı inverterin temel devresi gösterilmiştir. Yarı ilekten güç anahtarı olarak IGBT kullanılmıştır.

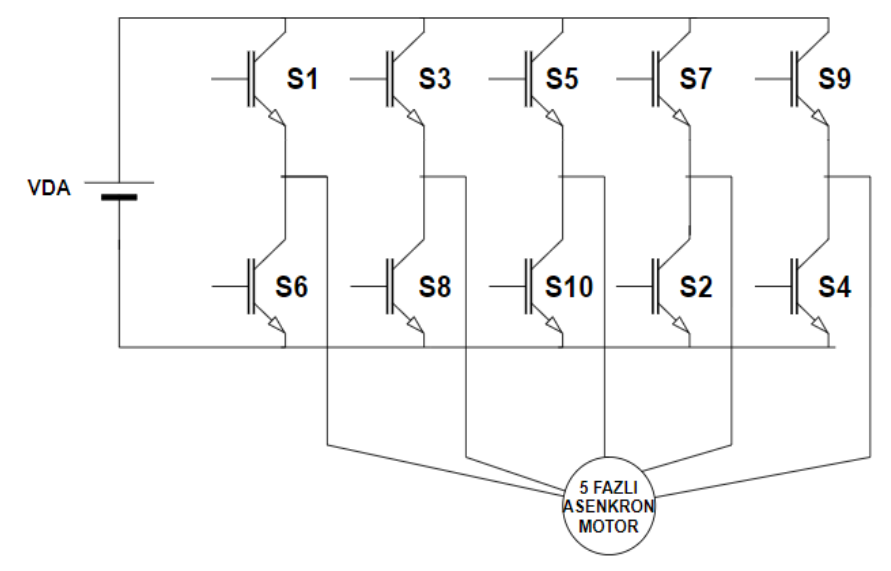

Şekil 2. 5 fazl gerilim kaynakl inverterin temel devresi

Çok fazlı inverterin her bir bacağı bir fazı temsil ettiği için bacak sayısı artırılarak n sayıda faz üretilebilir [7]. Asenkron motoru sürmek için üst anahtarlardan üç anahtar ve alt anahtarlardan iki anahtar aynı zamanda açıktır [8]. Bu durumun tam tersi de geçerlidir. İnverterin bir bacağını oluşturan iki 
anahtar birbirini tamamlar. Örneğin S1 anahtarı açıkken S6 anahtarı kısa devreyi önlemek için kapalıdır.

Çok seviyeli inverterlerde seviye sayısı artırılarak çıkış dalga şeklinin sinüzoidal biçime yaklaşması sağlanmasının yanı sıra farklı modülasyon teknikleri kullanılarak da çıkış dalga şeklinin sinüzoidal biçime yaklaşması yapılabilmektedir. Bu yöntemler darbe genişlik modülasyon tekniği olarak isimlendirilir [9]. Bu çalışmada darbe genişlik modülasyon tekniği olarak sinüzoidal darbe genişlik modülasyon tekniği kullanılmıştır.

\section{Sinüzoidal darbe genişlik modülasyon tekniği}

Sinüzoidal darbe genişlik modülasyon tekniği en çok bilinen ve endüstride yaygın olarak kullanılan bir yöntemidir. Dijital modülasyon tekniklerindeki gibi karmaşık hesaplara gerek duyulmaması ve analog olarak gerçekleştirebilmesi en büyük avantajlarıdır. Referans sinüzoidal dalga ile yüksek frekanslı taşıyıcı dalganın karşılaştırılması sonucu inverterde bulunan yarı iletken anahtarlama elemanlarının açıklık ve kapalılık süreleri belirlenir [10]. Şekil 3 'te gerilim kaynaklı beş fazlı inverter devresi gösterilmiştir. Her bacakta bulunan anahtarlar, üst veya alt anahtarın durumuna göre 1 veya 0 değerini alabilirler. Eğer sinüzoidal referans gerilimin değeri taşıyıcı üçgen dalga geriliminin değerinden büyük ise inverterin üst kolundaki anahtarlar iletimdedir, küçük ise alt kolundaki anahtarlar iletimdedir.

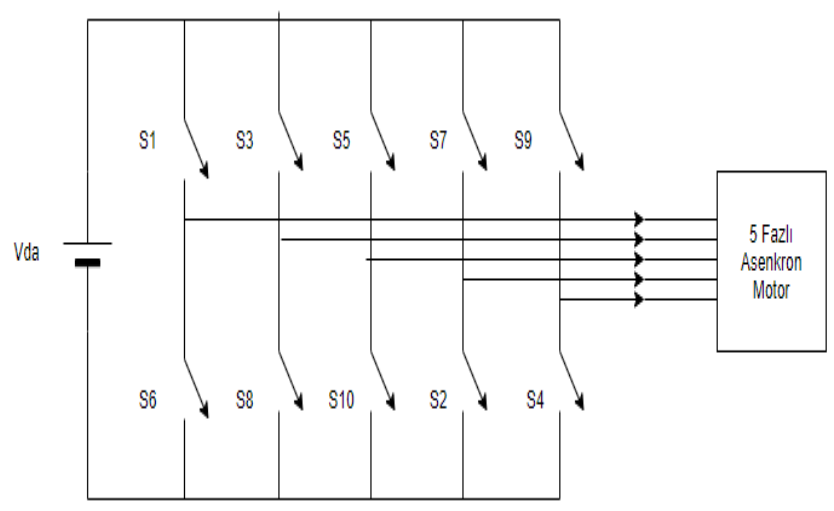

Şekil 3. Gerilim kaynaklı 5 -fazlı inverter

Sinüzoidal darbe genişlik modülasyon tekniğinde; referans sinüzoidal dalganın genliğinin taşıyıcı üçgen dalganın genliğine oranı modülasyon indeksi $\left(M_{i}\right)$ şeklinde tanımlanır [9]. $M_{i}$ denklem 1'deki gibi ifade edilir.

$$
M_{i}=\frac{V_{\text {ref }}}{V_{\text {üçgen }}}
$$

$\mathrm{V}_{\text {ref }}=$ Referans sinüzoidal dalganın tepe değeri

$\mathrm{V}_{\text {üçgen }}=$ Taşıyıcı üçgen dalganın tepe değeri

$M_{i}$ çıkış genliğinin ayarlanması için değiştirilmektedir. Böylece değişken genliğe sahip bir sürücü sistem elde edilmektedir [10]. $M_{i}{ }^{\prime}$ nin 0 ile 1 arasında değişmesi istenir.
Referans sinyalin genliği ile modülasyon indeksi ayarlanır [11].

Sinüzoidal darbe genişlik modülasyon tekniğinde taşıyıcı üçgen dalganın frekansının $\left(f_{\text {üçgen }}\right)$ referans sinüzoidal dalga frekansına $\left(f_{\text {ref }}\right)$ oranına frekans modülasyon indeksi $\left(m_{f}\right)$ denir ve frekans modülasyon indeksi verilen denklem 2 'deki gibi ifade edilir.

$$
m_{f}=\frac{f_{\text {üçgen }}}{f_{\text {ref }}}
$$

Taşıyıcı üçgen dalganın frekansının değeri seçilirken, $m_{f}$ değerinin tamsayı olmasına ve aynı zamanda $m_{f}^{\prime}$ in 3'ün katı olması durumuna dikkat edilmesi gerekir. $m_{f}^{\prime}$ in tam sayı olmadığı durumlarda çıkış geriliminde DA harmonik bileşenleri mevcut olacaktır [10].

\section{Beş fazlı asenkron motor modeli}

Asenkron motorda, stator-rotor kuplaj terimi rotorun pozisyonuna bağlı olarak değişim gösteren bir fonksiyondur [12]. Bu nedenle rotor pozisyonuna $(\theta)$ bağlı olarak rotor ile stator arasındaki ortak endüktansların, sinüzoidal şekilde değişmesi sonucu gerilim denklemlerinde zaman ile değişen katsayılar ortaya çıkar. Bu durum, 5 faz düzleminde motorun dinamik davranışını ifade eden denklemlerin karmaşık olmasına ve beş faz düzleminde motor modelinin çözümünün zor bir şekilde gerçekleştirilmesine neden olur. Fakat asenkron motorun matematiksel modelinin beş faz düzleminden herhangi bir referans hiz ile dönen d-q-0 referans çerçevesine aktarılmasıyla beraber rotorun hızına ve zamana bağlı olarak değişen ortak endüktansları içeren diferansiyel denklemler sabit endüktanslara sahip diferansiyel denklemlere dönüşmüş olur [13].

Yapılan çalışmada beş fazlı asenkron motorun simulink modeli d-q-0 eşzamanlı olarak dönen referans çatı dönüşümleri ile oluşturulmuştur. Şekil 4'te beş fazlı asenkron motorun d-q-0 eksenli eşdeğer devresi verilmiştir.
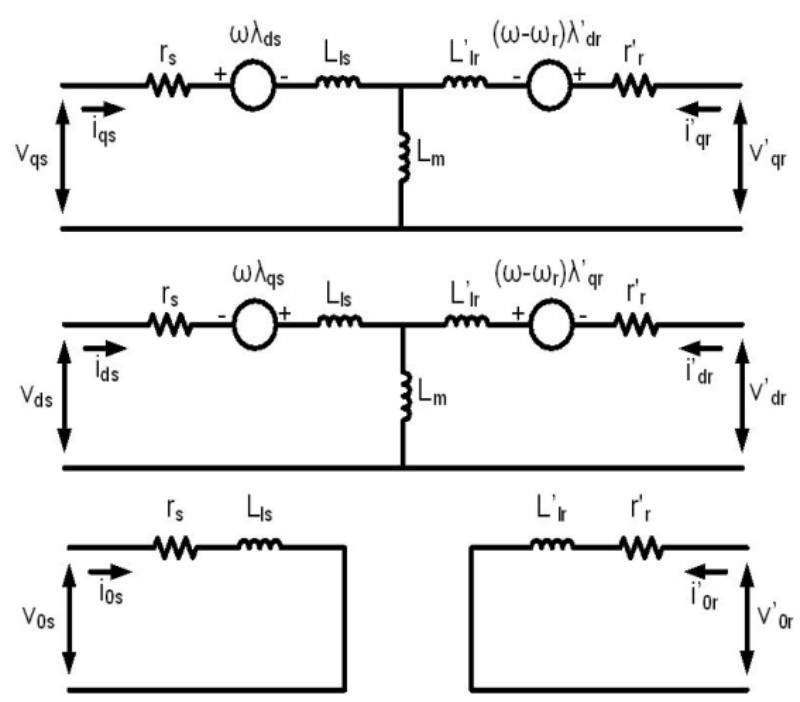

Şekil 4. Beş fazlı asenkron motorun d-q-0 eşdeğer devresi [5] 
Beş faz ile üç faz modeli arasındaki tek fark x-y bileşenlerinin varlığıdır. Rotor çubukları kısa devre edildiğinden rotor sargısında $x-y$ bileşenleri görünmez. Stator ve rotor için, rotor çubuklarının kısa devre olmasından ve stator sargısının yıldız bağlantısı nedeniyle 0 bileşen denklemleri dikkate alınmayabilir [5].

\section{Denklemler}

Beş fazlı asenkron motorun dengeli durumdaki stator gerilimleri aşağıdaki denklem (3)-(7) ‘de verilmiştir.

$$
\begin{gathered}
V_{a}=\sqrt{2} \cdot V_{r m s} \cdot \sin \left(\omega_{t}\right) \\
V_{b}=\sqrt{2} \cdot V_{r m s} \cdot \sin \left(\omega_{t}-\frac{2 \pi}{5}\right) \\
V_{c}=\sqrt{2} \cdot V_{r m s} \cdot \sin \left(\omega_{t}-\frac{4 \pi}{5}\right) \\
V_{d}=\sqrt{2} \cdot V_{r m s} \cdot \sin \left(\omega_{t}+\frac{4 \pi}{5}\right) \\
V_{e}=\sqrt{2} \cdot V_{r m s} \cdot \sin \left(\omega_{t}+\frac{2 \pi}{5}\right)
\end{gathered}
$$

5 fazlı asenkron motorun stator ve rotor büyüklüklerinin $d-q$ referans düzlemine taşınması denklem (8) 'de verilen dönüşüm matrisi ile gerçekleştirilmektedir.

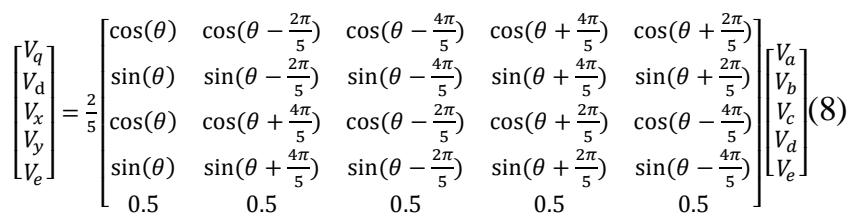

Stator tarafına ait gerilim denklemleri denklem (9) -(13)'te verilmiştir.

$$
\begin{gathered}
V_{d s}=R_{s} \cdot i_{d s}-\omega_{e} \cdot \psi_{q s}+\frac{\psi_{d s}}{d t} \\
V_{q s}=R_{s} \cdot i_{q s}+\omega_{e} \cdot \psi_{d s}+\frac{\psi_{q s}}{d t} \\
V_{x s}=R_{s} \cdot i_{x s}+\frac{\psi_{x s}}{d t} \\
V_{y s}=R_{s} \cdot i_{y s}+\frac{\psi_{y s}}{d t} \\
V_{0 s}=R_{s} \cdot i_{0 s}+\frac{\psi_{0 s}}{d t}
\end{gathered}
$$

Rotor tarafina ait gerilim denklemleri denklem (14) -(18)'de verilmiştir.

$$
\begin{gathered}
V_{d r}=R_{r} \cdot i_{d r}-\left(\omega_{e}-\omega\right) \cdot \psi_{q r}+\frac{\psi_{d r}}{d t} \\
V_{q r}=R_{r} \cdot i_{q r}+\left(\omega_{e}-\omega\right) \cdot \psi_{d r}+\frac{\psi_{q r}}{d t} \\
V_{x r}=R_{r} \cdot i_{x r}+\frac{\psi_{x r}}{d t}
\end{gathered}
$$

$$
\begin{aligned}
& V_{y r}=R_{r} \cdot i_{y r}+\frac{\psi_{y r}}{d t} \\
& V_{0 r}=R_{r} \cdot i_{0 r}+\frac{\psi_{0 r}}{d t}
\end{aligned}
$$

İndüklenen Moment ve Rotor Hızı denklemleri denklem (19) ve denklem (20)'de verilmiştir.

$$
\begin{gathered}
T_{e}=\frac{5}{2} \frac{P}{2}\left(\psi_{d s} i_{q s}-\psi_{q s} i_{d s}\right) \\
\omega_{r}=\int \frac{P}{2 j}\left(T_{e}-T_{L}\right)
\end{gathered}
$$

\section{Matlab/Simulink modeli}

Benzetim modelinde kullanılan beş fazlı asenkron motorun parametreleri tablo 1'de verilmiştir.

Tablo 1. Beş fazlı asenkron motor parametreleri [11]

\begin{tabular}{|l|c|}
\hline \multicolumn{1}{|c|}{ Motor parametreleri } & Değeri \\
\hline Güç $(\mathrm{P})$ & $2 \mathrm{HP}$ \\
\hline Gerilim(V) & $220 \mathrm{~V}$ \\
\hline Akım $(\mathrm{A})$ & $2.5 \mathrm{~A}$ \\
\hline Frekans(f) & $50 \mathrm{~Hz}$ \\
\hline Hız(n) & $1440 \mathrm{dev} / \mathrm{dk}$ \\
\hline Stator direnci $\left(R_{S}\right)$ & $10 \Omega$ \\
\hline Rotor direnci $\left(R_{r}\right)$ & $6.3 \Omega$ \\
\hline Stator kaçak indüktansı $\left(L_{l s}\right)$ & $0.04 \mathrm{H}$ \\
\hline Rotor kaçak indüktansı $\left(L_{l r}\right)$ & $0.04 \mathrm{H}$ \\
\hline Ortak indüktans $\left(L_{m}\right)$ & $1.05 \mathrm{H}$ \\
\hline Kutup sayısı $(\mathrm{p})$ & 4 \\
\hline Sürtünme katsayısı & $0.03 \mathrm{Kgm}$ \\
\hline Eylemsizlik katsayıs1 & $0.0015 \mathrm{Nms}$ \\
\hline
\end{tabular}

Şekil 5'te sünüzoidal referans gerilim değeri ile taşıyıcı üçgen dalga geriliminin karşılaştırma modeli verilmiştir.

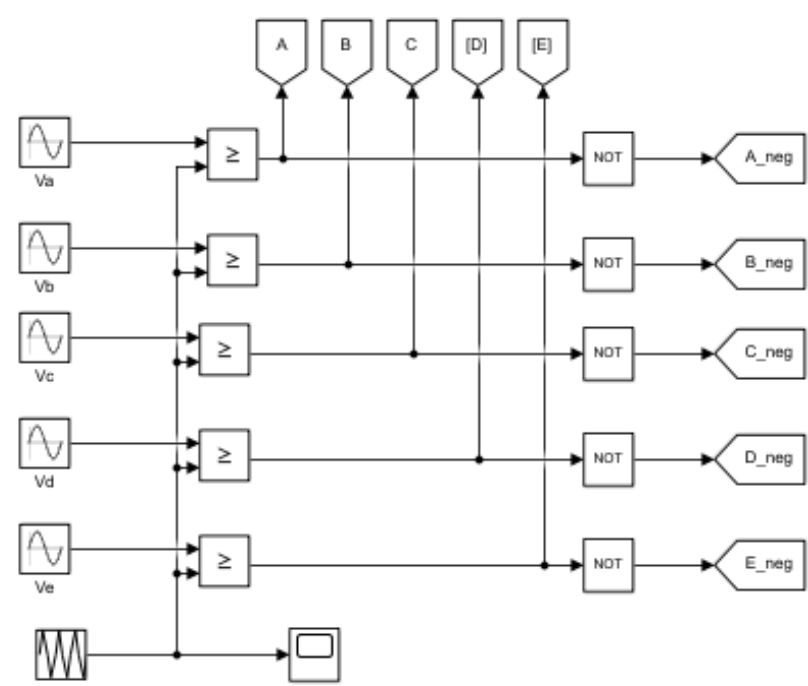

Şekil 5. Referans sinüzoidal dalga ile yüksek frekanslı taşıyıcı dalganın karşılaştırma modeli 
Sinüzoidal darbe genişlik modülasyon tekniğinde, sinüzoidal referans sinyallerin modülasyon indeksi 0.95 iken taşıyıcı üçgen sinyal ile karşılaştırılmıştır. Taşıyıcı üçgen sinyalin frekansı $m_{f}^{\prime}$ in tamsayı ve 3'ün katı olması sağlanacak şekilde $1.5 \mathrm{kHz}$ olarak seçilmiştir. Bu çalışma durumlarına ilişkin çıkış sinyali Şekil 6'da verilmiştir. Şekilde sinüzoidal dalganın genliği taşıyıcı üçgen dalganın genliğinden büyük olduğu kısimda anahtar 1 konumunda tersi durumda anahtar 0 konumundadir.

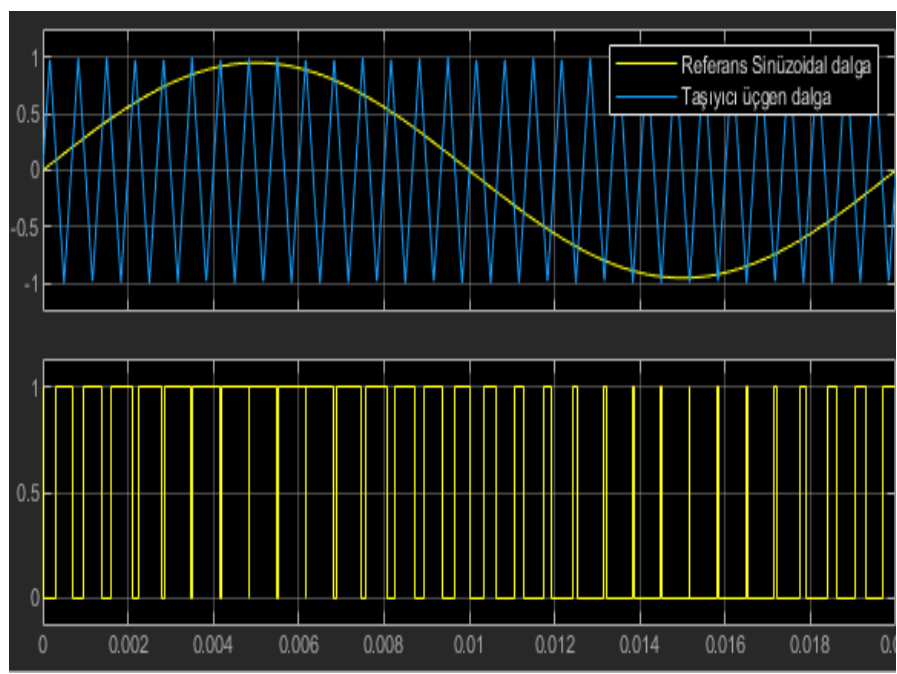

Şekil 6. Sinüzoidal darbe genişlik modülasyon tekniği ile sinüzoidal referans sinyal ile taşıyıcı üçgen sinyalin karşılaştırılması çıkış sinyali

Sinüzoidal darbe genişlik modülasyon yöntemi ile beş fazlı asenkron motorun matlab/simulink modeli Şekil 7'de verilmiştir.

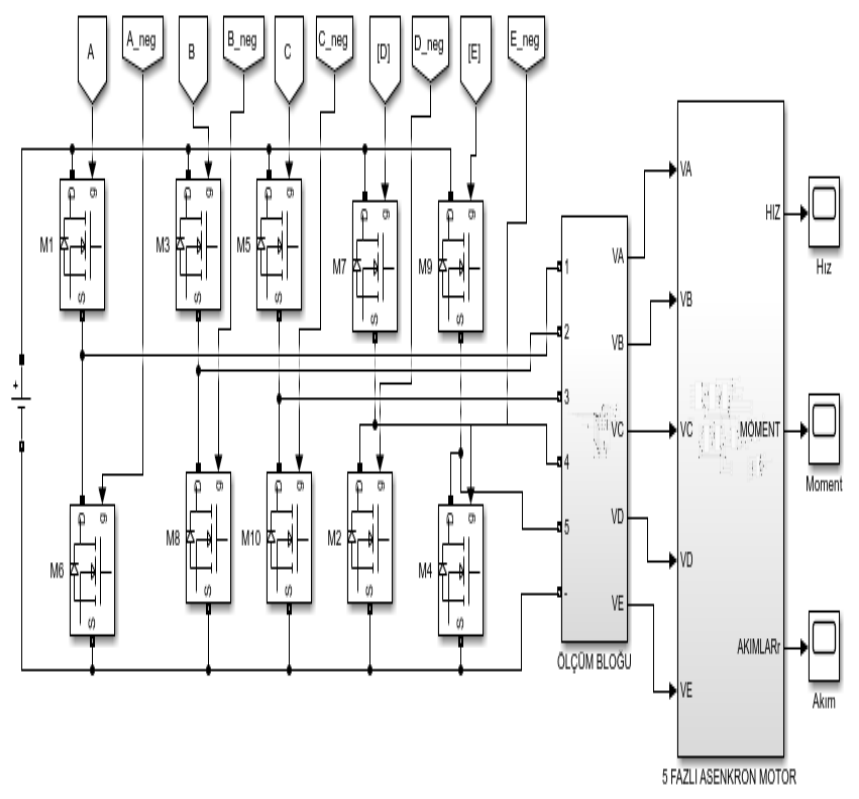

Şekil 7. Sinüzoidal darbe genişlik modülasyon yöntemi ile beş fazl l asenkron motor modeli

\section{Bulgular ve Tartışma}

Sinüzoidal darbe genişlik modülasyon yöntemi kullanılarak modellenen 5 fazlı asenkron motor 0-0.3 sn arasında yüksüz 0.3-0.5 sn arasında 8.83 N.m yük momenti ile yüklenmiştir. Modülasyon indeksi 0.95 'e ayarlanarak stator faz akımları, hız ve moment grafikleri elde edilmiştir. Şekil 8'de modülasyon indeksi 0.95 iken stator faz akımları grafiği verilmiştir. Şekil 9 ve Şekil 10 'da modülasyon indeksi 0.95 iken hız ve moment grafikleri verilmiştir.

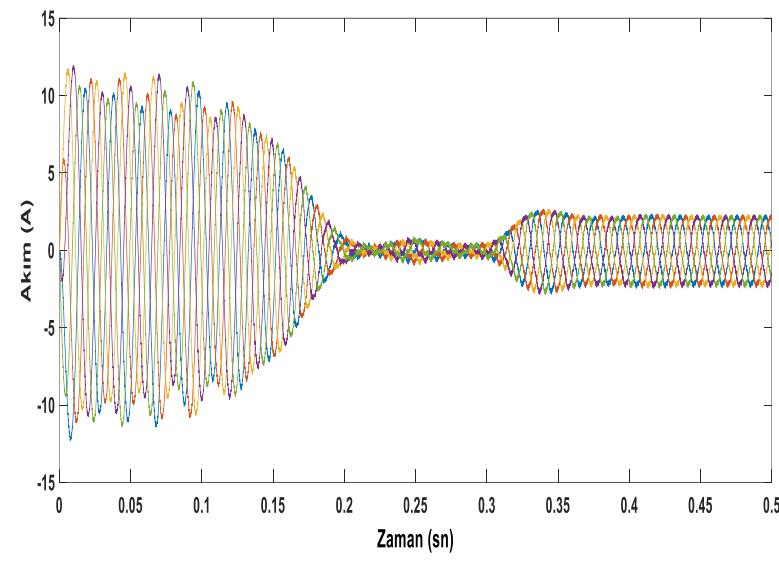

Şekil 8. Modülasyon indeksi 0.95 iken stator faz akımlarızaman grafiği

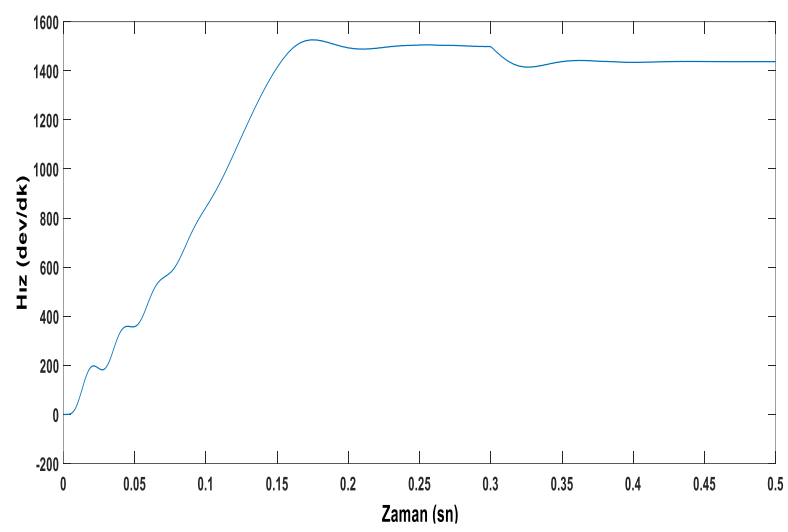

Şekil 9. Modülasyon indeksi 0.95 iken hız-zaman grafiği

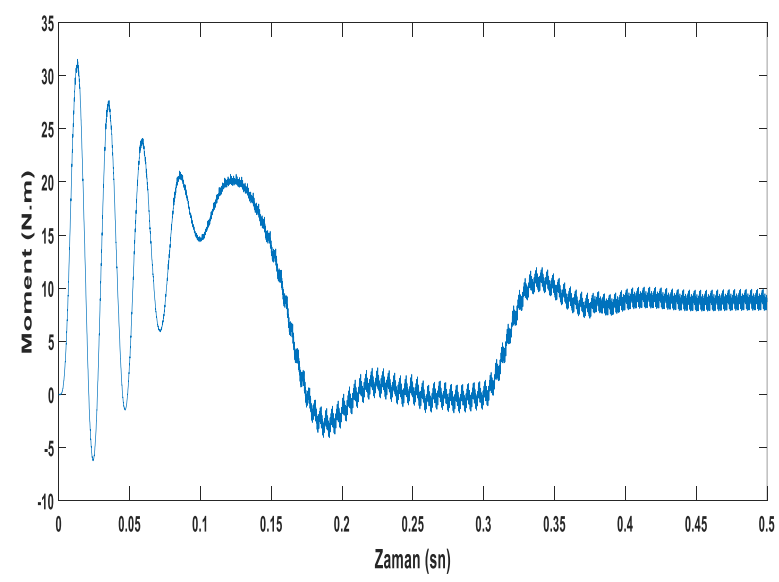

Şekil 10. Modülasyon indeksi 0.95 iken moment - zaman grafiğ $i$ 
Aynı çalışma şartları altında modülasyon indeksi 0.8 ' e ayarlanarak motor çalıştırıldığında stator faz akımları, hız ve moment grafikleri elde edilmiştir. Şekil 11'de modülasyon indeksi 0.8 iken stator faz akımları grafiği verilmiştir. Şekil 12 ve Şekil 13'te modülasyon indeksi 0.8 iken hız ve moment grafikleri verilmiştir.

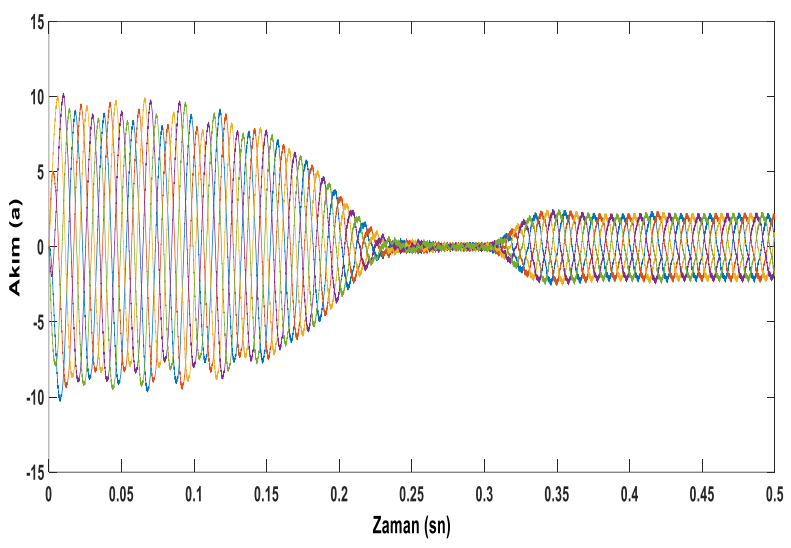

Şekil 11. Modülasyon indeksi 0.8 iken stator faz akımlarızaman grafiği

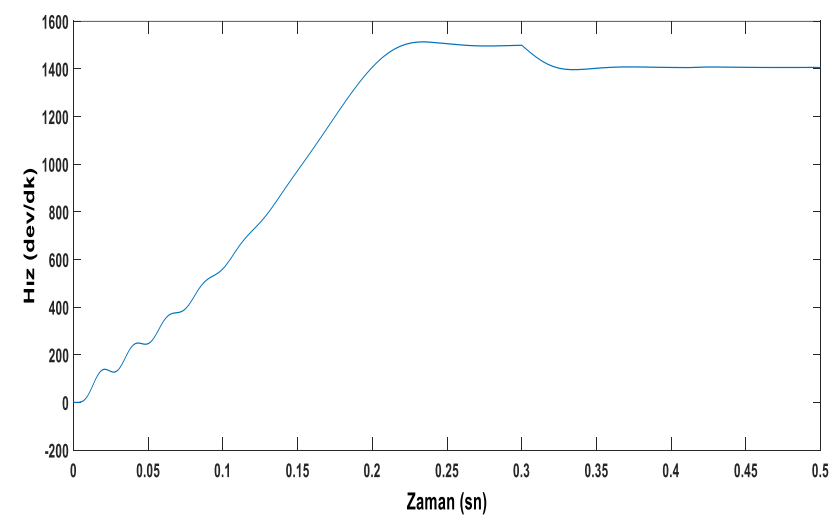

Şekil 12. Modülasyon indeksi 0.8 iken hız-zaman grafiğ $i$

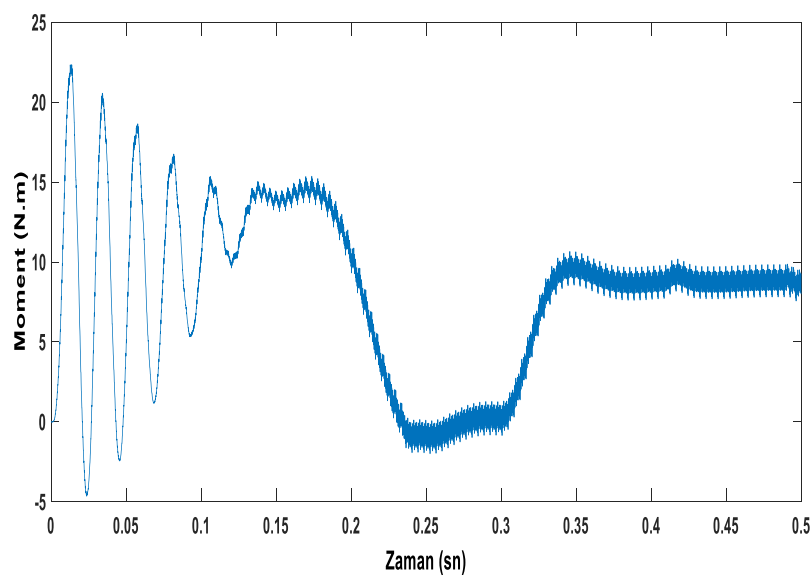

Şekil 13. Modülasyon indeksi 0.8 iken moment-zaman grafiğ $i$

\section{Sonuç}

$\mathrm{Bu}$ çalışmada beş fazlı asenkron motor sinüzoidal darbe genişlik modülasyon tekniği (SDGM) kullanılarak çalıştırılmış ve benzetim sonuçları elde edilmiştir. SDGM tekniğinde gerilim kontrolü modülasyon indeksi ile yapılabilmektedir. Çalışmada 0.8 ve 0.95 modülasyon indeksleri için motorun akım, hız ve moment grafikleri elde edilmiştir.

Benzetim sonuçlarına bakıldığında;

- $M_{i}=0.95$ durumunda motorun giriş gerilimi daha yüksek olduğundan sürekli duruma geçiş süresi $M_{i}=0.8$ olduğu duruma göre daha hızlı olmuştur.

- $\quad M_{i}=0.95$ durumunda motorun çekmiş olduğu akım hem geçici rejimde hem de sürekli rejimde, $M_{i}=0.8$ durumuna göre daha fazladir.

- $M_{i}=0.95$ durumunda motorun kalkış momenti $M_{i}=0.8$ olduğu duruma göre daha fazladır.

- Her iki durumda da motor aynı değerdeki yük momentiyle yüklenmiş ve $M_{i}=0.8$ durumunda iken motor yüklendiğinde hızdaki düşüş miktarı $M_{i}=0.95$ durumundaki düşüş miktarına göre daha fazla olmuştur.

\section{Biyografi}

Taşkın E: 1994 yılında Elazı̆̆'da doğdu. Lisans öğrenimini 2017 yılında Firat Üniversitesi'nde tamamladı. 2020 yılında mart ayında doktora programına başlad1.100/2000 doktora bursu programına kayıtlıdır. Elektrikli ve hibrit araçlar üzerinde çalışmaktadır.

Özdemir M: 1958 yılında Elazığg'da doğdu. Lisans, yüksek lisans ve doktora derecelerini sirasiyla 1980, 1984 ve 1993 yıllarında Fırat Üniversitesi’nde tamamladı. Şu anda Fırat Üniversitesi'nde Doç. Dr. olarak görev yapmaktadır. Elektrik makinaları ve sürücüleri üzerinde çalışmalar yapmaktadır.

Sarıgül İ: 1995 yılında Elazığ'da doğdu. Lisans ve yüksek lisansını Fırat Üniversitesi'nde tamamladı. İnönü Üniversitesi'nde doktora eğitimine devam ediyor. Şu anda İnönü Üniversitesi'nde Elektrik Elektronik Mühendisliği bölümünde araştırma görevlisi olarak görev yapmaktadır. Elektrik makinaları ve sürücüleri üzerinde çalışmaktadır.

\section{Teşekkür}

Ezgi TAŞKIN 100/2000 YÖK Doktora Bursu programı kapsamında desteklenmiştir. 


\section{Kaynaklar}

[1] Y. Zhao, \& T.A. Lipo, "Space vector PWM control of dual three-phase induction machine using vector space decomposition", IEEE Transactions on industry applications, vol. 31, no. 5, pp. 1100-1109, 1995.

[2] S. Smith, "Developments in power electronics, machines and drives", Power Engineering Journal, vol. 16, no. 1, pp. 13-17, 2002.

[3] G.K. Singh, "Multi-phase induction machine drive research-A survey", Electric Power Systems Research, vol. 61, no. 2, pp. 139-147, 2002.

[4] N. A. Dattu and M. R. Rashmi, "Modeling of five phase induction motor drive", 2017 International Conference on Technological Advancements in Power and Energy (TAP Energy), pp. 1-5, 2017.

[5] K.S.Aher, \& A.G.Thosar, "Modeling and Simulation of Five Phase Induction Motor Using Matlab Simulink", International Journal of Engineering Research and Applications, vol. 6, no. 5, pp.1-8, 2016.

[6] Çetin İ. \& Schusky W., Elektrik Motörleri(motorlar1), Fatih Yayınevi, 1987, İstanbul.

[7] G. Palak Sharma, S. Rangari, "Simulation of inverter fed five phase induction motor.", Int. J. of Science and Research, vol. 2, no. 2, pp. 127-132 Feb. 2013
[8] D.Sami, and E.E. EL-Kholy, "Modeling of Five Phase Induction Motor Drive", paper presented at the 2017 International Conference on Technological Advancements in Power and Energy (TAP Energy), Kollam, India, Dec. 21-23, 2017.

[9] M. M. Akay, “3 fazlı uzay vektör PWM kontrollü eviricinin FPGA tabanlı kosimülasyonu," Yüksek Lisans Tezi, Dicle Üniversitesi Fen Bilimleri Enstitüsü, Diyarbakır, 2019.

[10] M. Boylu “Asenkron Motorun Hiz Kontrolü”, Yüksek Lisans Tezi, İstanbul Teknik Üniversitesi Fen Bilimleri Enstitüsü, İstanbul, 2010

[11] M. Sowmiya, G. Renukadevi, \& K. Rajambal, "IFOC of five-phase induction motor drive", In 2013 International Conference on Power, Energy and Control (ICPEC) IEEE, pp. 304-309, Feb. 2013.

[12] N. Güzel, "3-fazlı asenkron makinanın modellenmesi ve PWM ile hiz kontrolü," Yüksek Lisans Tezi, Sakarya Üniversitesi Fen Bilimleri Enstitüsü, Sakarya, 2005.

[13] R. Rahmatullah, M.F. Demir, \& N.F.O.Serteller, "Asenkron Motorların DQ Eksende Üç Referans Çerçevesinde Matlab/Simulink ile İncelenmesi”, Innovations in Intelligent Systems and ApplicationsConference(ASYU), IEEE , October . 2020. 